\title{
BMJ Open Prevalence of restless legs syndrome in functional movement disorders: a case- control study from the Czech Republic
}

\author{
Tereza Serranová, ${ }^{1}$ Matěj Slovák, ${ }^{1}$ David Kemlink, ${ }^{1}$ Karel Šonka, ${ }^{1}$ Mark Hallett, ${ }^{2}$ \\ Evžen Růžička ${ }^{1}$
}

To cite: Serranová T, Slovák M, Kemlink D, et al. Prevalence of restless legs syndrome in functional movement disorders: a case-control study from the Czech Republic. BMJ Open 2019;9:e024236. doi:10.1136/ bmjopen-2018-024236

- Prepublication history and additional material for this paper are available online. To view these files, please visit the journal online (http://dx.doi. org/10.1136/bmjopen-2018024236).

TS and MS contributed equally.

Received 16 May 2018

Revised 24 November 2018

Accepted 27 November 2018

Check for updates

(c) Author(s) (or their employer(s)) 2019. Re-use permitted under CC BY-NC. No commercial re-use. See rights and permissions. Published by BMJ.

${ }^{1}$ Department of Neurology and Center of Clinical Neuroscience, Charles University in Prague, 1st Faculty of Medicine and General University Hospital in Prague,

Prague, Czech Republic

${ }^{2}$ Human Motor Control Section,

Medical Neurology Branch,

National Institute of Neurological

Disorders and Stroke, National

Institutes of Health, Bethesda,

Maryland, USA

Correspondence to

Dr Tereza Serranová;

tereza.serranova@vfn.cz

\section{ABSTRACT}

Objectives The prevalence of restless legs syndrome (RLS) in functional movement disorders (FMD) is not known. Patients with FMD often present with multiple motor and sensory symptoms. Some of these symptoms might be due to comorbid RLS. Therefore, our objective was to evaluate possible association between FMD and RLS.

Design Case-control study.

Setting Movement Disorders Center, 1st Faculty of Medicine and General University Hospital in Prague, Czech Republic.

Participants 96 consecutive patients with clinically established FMD (80 females, mean age (SD) 45.0 (13) years), and 76 matched controls.

Primary and secondary outcome measures The primary outcome measure was prevalence of RLS based on updated International RLS Study Group criteria. Secondary outcome measures included prevalence of periodic limb movements (PLM) using actigraphy; pain, motor and sensory symptoms in lower limbs; organic comorbidities and medication affecting RLS.

Results RLS criteria were fulfilled in $43.8 \%$ of patients (95\% Cl 34 to 54$)$ and in $7.9 \%$ of controls $(95 \% \mathrm{Cl} 3$ to 17 , $\mathrm{p}<0.00001$ ). Both RLS and PLM indices (PLMi) $\geq 22.5 /$ hour were found in $21.2 \%$ of patients with FMD and $2.6 \%$ of controls. Patients with FMD with RLS had a higher mean PLMi $(p<0.001)$ and a higher proportion of PLMi $\geq 22.5 /$ hour $(p<0.01)$ than RLS-negative patients. Patients with RLS had higher prevalence of pain and sensory symptoms in lower limbs, no difference was found in medication and prevalence of organic comorbidities in patients with FMD with and without RLS.

Conclusions We found an increased prevalence of RLS in patients with FMD. Clinical diagnosis of RLS was supported by actigraphic measurement of clinically relevant PLM in a significant proportion of patients with FMD. Although functional motor and sensory symptoms may mimic RLS, RLS may be unrecognised in patients with FMD. This finding may have clinical implications in management of FMD, and it raises the possibility of common pathophysiological mechanisms of FMD and RLS/ PLM.

\section{INTRODUCTION}

Functional (psychogenic) movement disorders (FMD) are common neurological

\section{Strengths and limitations of this study}

- This is the first study to assess prevalence of restless legs syndrome (RLS) in patients with clinically established diagnosis of functional movement disorders (FMD) based on positive diagnostic signs of inconsistency and incongruence.

- Case-control study design with relatively large sample of patients with FMD and matched controls was used.

- Updated International RLS Study Group criteria for the diagnosis of RLS were applied.

- Objective actigraphic assessment of PLM was performed using validated methodology to control for false-positive RLS cases.

- The main limitation of the study results from introduction of new polysomnographic criteria for PLM in the course of the study which could not be implemented in this actigraphic study.

manifestations, clinically defined by abnormal movement control that is significantly altered by distraction or non-physiological manoeuvres and that is clinically incongruent with movement disorders known to be caused by neurological disease. ${ }^{1}$

Patients with FMD frequently present with a complex and variable motor phenotype. In addition, they often report sensory symptoms and pain in multiple body regions, mood disorders, fatigue and sleep problems. ${ }^{23}$ Restless legs syndrome (RLS) is defined by an urge to move a body part (usually the lower limbs) typically accompanied by a wide range of sensory symptoms. ${ }^{4}$ Higher prevalence of RLS has been reported in numerous and pathophysiologically heterogeneous conditions. However, a recent systematic review of evidence confirmed higher prevalence of RLS only in kidney disease and iron deficiency and possible association in some cardiovascular diseases in women, diabetes (and neuropathy), migraine and dopaminergic treatment in Parkinson's disease. ${ }^{5}$ RLS prevalence in patients with FMD has not been 
studied thus far. We hypothesised that patients with FMD may have a higher prevalence of RLS than is reported in the general population, and some of the sensory and motor phenomena observed in patients with FMD may be due to unrecognised RLS.

The main objective of this study was to assess the prevalence of RLS in a group of patients with FMD and/or functional weakness, compared with a matched control group. RLS was defined according to the current diagnostic criteria. ${ }^{4}$ In addition, the presence of periodic limb movements (PLM) that are considered as an objective biomarker of RLS was assessed by actigraphy. ${ }^{46}$

Illness beliefs and unexplained somatosensory input may play an important role in the development of functional neurological symptoms. ${ }^{7}$ To find out whether RLS could contribute to the later development of FMD, we also aimed to analyse the time relationship between the onset of FMD and RLS.

Additionally, factors that can affect RLS prevalence (age, organic comorbidities including migraine, depression, anxiety and medication) were also considered in the analysis. ${ }^{8-10}$ Furthermore, we studied the relationship between the FMD phenotype, the prevalence of RLS/PLM and non-motor symptoms such as daytime sleepiness, fatigue and sensory symptoms and pain in lower limbs.

\section{METHODS}

\section{Subjects}

We recruited 115 consecutive patients (94 females, mean age (SD) 44.8 (13) years) diagnosed with clinically definite FMD according to the diagnostic criteria of Gupta and Lang between October 2014-December 2016. ${ }^{11}$ The diagnosis of FMD was based on detailed clinical interviews and examination by an experienced movement disorders specialist (TS) finding positive signs of functional weakness and/or abnormal movements inconsistent in time and incongruent with known movement disorders. ${ }^{1}{ }^{12} 13$ FMD duration was recorded.

During the same time period, 76 unrelated sex-matched and age-matched control subjects were recruited (66 females, mean age (SD) 44.2 (11) years) from database of healthy subjects willing to participate in clinical studies. In all controls, a complete medical history was recorded, and full neurological examination was performed by TS or MS. Only controls without neurological symptoms or signs of nervous system disorder affecting motor function (except for those corresponding to RLS) were included in the study. Both patients and controls with known kidney disease, iron deficiency or pregnancy were not included in the study. ${ }^{5}$

\section{Motor symptoms}

All motor symptoms present during the examination in each patient with FMD were recorded and phenomenologically classified as functional weakness, tremor, dystonia, myoclonus, gait disorder, parkinsonism, speech disturbance or eye movement abnormalities. The frequency of each phenotype was calculated. The presence or absence of any motor symptoms in lower limbs was recorded from face to face interview and physical examination.

\section{Organic multimorbidity and medication}

To evaluate the cumulative effect of organic comorbidities on RLS frequency, we used a Comorbidity Index by Szentkiralyi $e t$ al which was calculated as a sum of the following conditions: diabetes, hypertension, myocardial infarction, obesity, stroke, cancer, renal disease, anaemia, thyroid disease, migraine and depression. One point was assigned for each present condition. ${ }^{9}$ Obesity was defined as current body mass index $>30 \mathrm{~kg} / \mathrm{m}^{2}$. The presence of general medical conditions included in the Modified Comorbidity Index was based on patients' medical reports and clinical interview. Migraine was diagnosed from clinical interview according to current diagnostic criteria. ${ }^{14}$

The subjects were considered to have depression either if they scored in Beck Depression Inventory (BDIII) $\geq 14$ or scored lower with a proven history of depression treated with antidepressants. ${ }^{15}$ In each subject, we recorded presence or absence of medication possibly interfering with RLS and PLM prevalence. Use of any antidepressants, for example, selective serotonin reuptake inhibitors (SSRI), serotonin-norepinephrine reuptake inhibitors (SNRI), trazodone, mirtazapine or tricyclics in monotherapy or combination, was scored 1 if present, 0 if absent. Similarly, use of medication that may reduce RLS and PLM symptoms, for example, gabapentinoids (pregabalin and gabapentin), dopaminergic drugs (dopamine agonists and levodopa) and opioids, was scored as 1 if the medication was present, 0 if absent. Additionally, we also recorded the use of betablockers that have been reported as related to RLS and PLM. ${ }^{10}$ The history of antidepressants administration initiated prior to RLS onset was taken into account for evaluation of RLS prevalence while the use of antidepressants in the time of actigraphy was considered for PLM prevalence analysis.

Neurological comorbidities other than migraine were recorded and stratified according to their possible association with RLS and Neurological Comorbidity Index was calculated as follows ${ }^{5}$ : the presence of a condition that has been associated with an increased frequency of RLS regardless of the level of evidence (ataxia, multiple system atrophy, multiple sclerosis, Parkinson's disease, peripheral neuropathy, polyneuropathy and radiculopathy, muscle disorder and stroke) -1 point; neurological comorbidity without association with RLS or no known neurological comorbidity (pure FMD) -0 points.

\section{RLS and PLM evaluation}

All the patients and control subjects were interviewed for the presence of RLS. Subjects were classified as RLS positive (RLS+) if they met all five revised criteria of the International Restless Legs Syndrome Study Group: (1) an urge to move the legs usually accompanied by uncomfortable and unpleasant sensations, (2) symptoms beginning or worsening during periods of rest or inactivity, (3) partial or total relief by movement, (4) occurrence or 
worsening in the evening or night and (5) occurrence of the above features is not solely accounted for as symptoms primary to another medical or a behavioural condition. All known RLS mimics were considered and excluded. ${ }^{4}$ Subjects with inconsistent reports on RLS symptoms and evident suggestibility during interview were classified as functional mimics and labelled as RLS negative (RLS-). Cases with atypical presentation of RLS symptoms and/or with possible confounds were additionally interviewed by an experienced sleep disorder specialist (KŠ, DK) and if there were any diagnostic doubts, the case was labelled as RLS-. In RLS+ subjects, the duration of their RLS symptoms, a family history of RLS in first-degree relatives and the severity of their RLS according to the International Restless Legs Scale (IRLS) were recorded. ${ }^{16}$

We determined the number of RLS+ patients in whom motor symptoms localised in lower limbs were attributable exclusively to RLS, that is, were characterised by an urge to move the legs, beginning or worsening during periods of rest or inactivity, relieved by movement, with occurrence or worsening in the evening or night.

For detection of PLM, all control subjects and 96 patients with FMD, regardless of RLS status, underwent actigraphy from big toes for three consecutive nights at home. In 19 patients with FMD, actigraphic assessment was not available because of their refusal to participate or due to complicated logistics. The actigraphic measurement and assessment were performed as published previously. ${ }^{17}$ We have evaluated the total number of limb movements and the total number of PLM. The PLM index (PLMi, number of individual movements per hour) was calculated by dividing the total number of PLM by number of hours in bed according to the subjects' diary. For statistical analysis, we considered the highest PLMi value out of three nights in each subject. A cut-off PLMi $\geq 22.5 /$ hour (corresponding to PLMi $\geq 15$ /hour in polysomnography) consistent with the International Classification of Sleep Disorders 3rd edition criteria was used for clinically relevant PLM positivity. ${ }^{6} 1017$

\section{Sensory symptoms and pain in lower limbs}

The presence or absence of sensory disturbances (ie, paresthesias or dysaesthesias) in lower limbs was recorded from face to face interview and physical examination in each subject. We also determined the number of RLS+ subjects with sensory symptoms in lower limbs exclusively attributable to RLS, that is, accompanying the urge to move the legs, beginning or worsening during periods of rest or inactivity, relieved by movement, with occurrence or worsening in the evening or night.

The presence of pain in lower limbs was recorded if subjects marked lower limb region on a PainDetect body figure as location of an important pain. ${ }^{18}$ Additionally, the mean pain intensity in relation to the body parts marked on the body figure within the last 4 weeks was evaluated using a Visual Analogue Scale ( $0=$ no pain, $10=$ maximum pain) .

\section{Questionnaires for non-motor symptoms}

Along with the BDI-II, the subjects also completed self-administered questionnaires to determine the prevalence of anxiety traits (State-Trait Anxiety Inventory, STAI X2), chronic fatigue (Fatigue Severity Scale) and daytime sleepiness (Epworth Sleepiness Scale, ESS). ${ }^{19-21}$

\section{Statistics}

Statistical analyses were performed using Dell Statistica V.13 (Software.dell.com, Dell, 2016). Testing for normality was performed using the Shapiro-Wilks W test. For descriptive statistics, continuous variables were summarised as mean $\pm \mathrm{SD}$ or median $\pm \mathrm{IQR}$, whereas categorical variables were summarised as number of subjects and percentage. Continuous variables were compared using Student's t-test or Mann-Whitney U test as appropriate, while categorical variables were compared using $\chi^{2}$ statistics. We used logistic regression models to assess the association between demographic, clinical and actigraphic variables and PLMi $\geq 22.5 /$ hour. Statistical significance was defined as alpha 0.05 , and the Bonferroni correction for multiple testing was used where necessary.

\section{Patient and public involvement}

No participants were involved with the study design.

\section{RESULTS}

\section{Clinical characteristics}

Demographic and clinical characteristics from 96 patients with FMD and 76 control subjects who completed the study including actigraphy are summarised in table 1 . Nineteen patients did not complete actigraphy due to personal, technical or logistical reasons and were not included in the statistical analysis.

There was a difference between the two groups in the Comorbidity Index which was higher in the patients group. This difference in the Comorbidity Index was due to significantly higher prevalence of migraine and depression in patients with FMD. Therefore, to control for somatic comorbidities we calculated a Modified Comorbidity Index (without including migraine and depression). No difference between patients with FMD and controls was found for the Modified Comorbidity Index, as well as for the rates of each of the somatic organic comorbidities (ie, diabetes, hypertension, myocardial infarction, obesity, stroke, cancer, anaemia and thyroid disease), and for the Neurological Comorbidity Index. Without considering migraine, 72 out of 96 patients had pure FMD, while in 24 patients $(25.0 \%)$ we observed a comorbid organic neurological condition. Two control subjects had incidental peripheral neuropathy without an impact on motor function. See table 1 and online supplementary material for details. Higher percentage of patients than controls was taking both antidepressants and drugs suppressing RLS/ PLM. No difference was found in the use of betablockers.

\section{RLS and PLM}

Results from the clinical RLS assessment and actigraphy are shown in detail in tables 2 and 3. RLS was diagnosed 
Table 1 Demographic and clinical characteristics

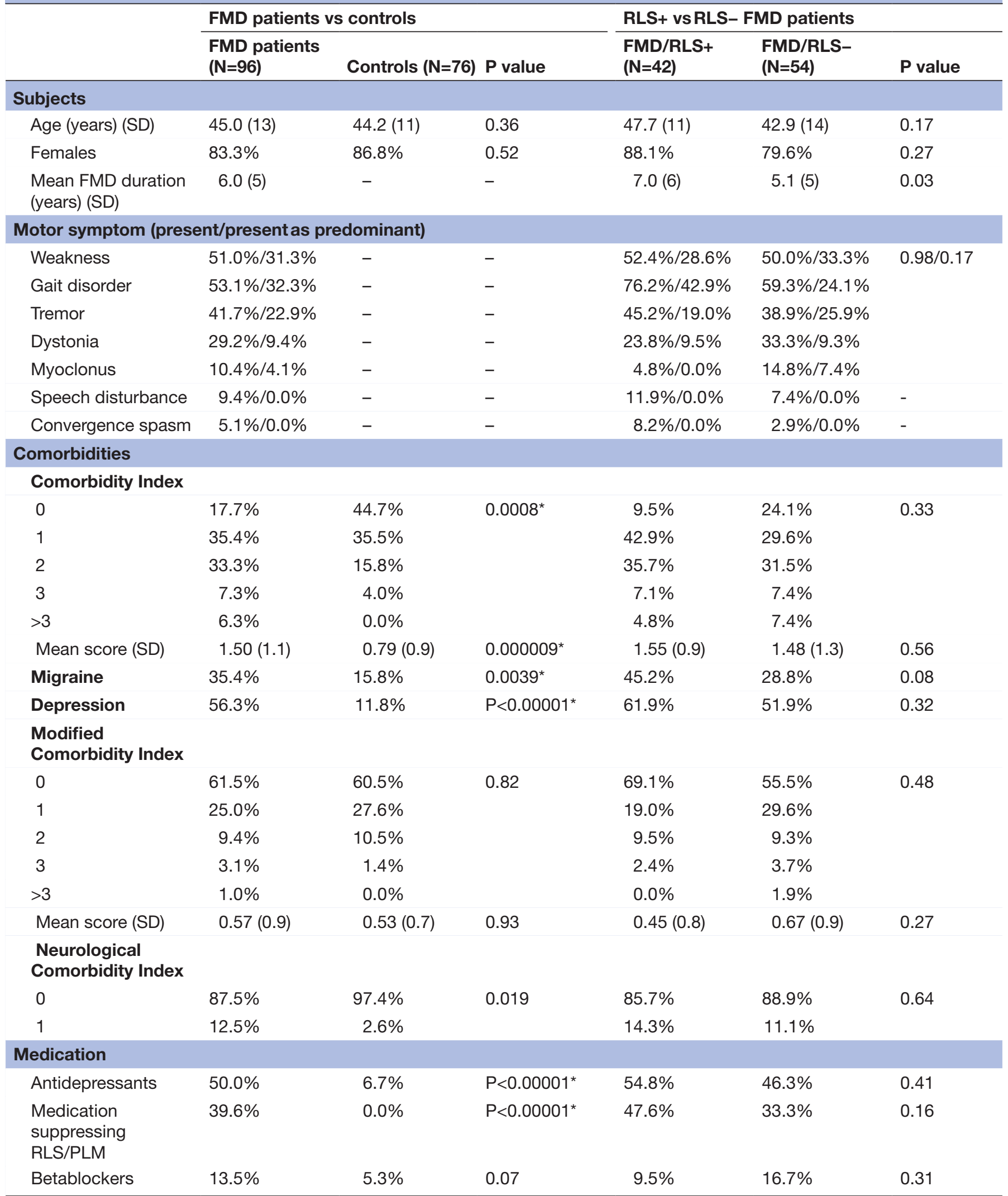

All intergroup comparisons were performed using Mann-Whitney $U$ test for quantitative parameters and $\chi^{2}$ for qualitative ones, $p$ values stand for nominal uncorrected results.

*Significant results after correcting for three comparisons among demographics and for seven comparisons among comorbidities and medication $(\mathrm{p}<0.05)$.

FMD, functional movement disorder; PLM, periodic limb movements; RLS, restless legs syndrome. 
Table 2 RLS assessment

\begin{tabular}{|c|c|c|c|}
\hline & \multicolumn{3}{|c|}{ FMD patients vs controls } \\
\hline & $\begin{array}{l}\text { FMD patients } \\
(\mathrm{N}=96)\end{array}$ & $\begin{array}{l}\text { Controls } \\
(\mathrm{N}=76)\end{array}$ & $P$ value \\
\hline RLS+ (N) & 42 & 6 & $<0.00001^{*}$ \\
\hline$\%(95 \% \mathrm{Cl})$ & 43.8 (34 to 54$)$ & 7.9 (3 to 17$)$ & \\
\hline $\begin{array}{l}\text { Mean IRLS score } \\
\text { in RLS+ (SD) }\end{array}$ & $23.6(7)$ & $7.0(6)$ & $0.00002^{*}$ \\
\hline \multicolumn{4}{|l|}{$\begin{array}{l}\text { Frequency of } \\
\text { RLS (number of } \\
\text { days in } 1 \text { week) }\end{array}$} \\
\hline$\leq 1$ & $12.5 \%$ & $60 \%$ & 0.03 \\
\hline $2-3$ & $27.5 \%$ & $40 \%$ & \\
\hline $4-5$ & $30 \%$ & $0 \%$ & \\
\hline $6-7$ & $30 \%$ & $0 \%$ & \\
\hline
\end{tabular}

\begin{tabular}{|c|c|c|c|}
\hline \multicolumn{4}{|l|}{$\begin{array}{l}\text { Duration of } \\
\text { RLS symptoms } \\
\text { (number of hours } \\
\text { per } 24 \text { hours) }\end{array}$} \\
\hline$<1$ & $20 \%$ & $80 \%$ & 0.04 \\
\hline $1-3$ & $42.5 \%$ & $20 \%$ & \\
\hline $3-8$ & $25 \%$ & $0 \%$ & \\
\hline$\geq 8$ & $12.5 \%$ & $0 \%$ & \\
\hline $\begin{array}{l}\text { Positive family } \\
\text { history of RLS in } \\
\text { RLS+† }\end{array}$ & $30.4 \%$ & $33.3 \%$ & 0.92 \\
\hline $\begin{array}{l}\text { Mean RLS } \\
\text { duration (years) } \\
\text { (SD) }\end{array}$ & $7.5(8)$ & $5.8(6)$ & 0.64 \\
\hline $\begin{array}{l}\text { Mean age at RLS } \\
\text { onset (years) } \\
\text { (SD) }\end{array}$ & 40.2 (13) & $34.5(9)$ & 0.30 \\
\hline
\end{tabular}

\section{RLS vs FMD}

onset

$\begin{array}{llll}\text { RLS before } & 26.8 \% & - & - \\ \text { FMD } & & - & - \\ \begin{array}{l}\text { Concurrent } \\ \text { onset }\end{array} & 26.8 \% & - & - \\ \text { RLS after FMD } & 46.3 \% & - & -\end{array}$

*Significant results $(p<0.05)$ after correcting for seven comparisons. †During interview, 22 patients did not know if RLS was present in their family history, and 18 patients had no family history of RLS. P values stand for nominal uncorrected results.

FMD, functional movement disorder; IRLS, International Restless Legs Scale; RLS, restless legs syndrome.

in $43.8 \%$ of patients and in $7.9 \%$ of controls $(p<0.0001$, corrected). The mean IRLS score was higher in the patients group. Sixty per cent of patients but no control subject had RLS symptoms present for more than 4 days in a week, $37.5 \%$ of patients but no control subjects had RLS symptoms duration longer than 3 hours per 24 hours. The prevalence of RLS, clinically relevant PLM (PLMi $\geq 22.5$ / hour) and combination of both were all significantly higher in patients with FMD than in controls. Patients with FMD had higher mean PLMi than controls $(\mathrm{p}=0.0003)$. RLS- controls had lower PLMi than RLS- patients with FMD ( $\mathrm{p}=0.03$ uncorrected, Mann-Whitney $\mathrm{U}$ test). There was no significant difference in the proportion of subjects with PLMi $\geq 22.5$ /hour between all controls and RLSpatients with FMD.

The duration of FMD symptoms did not significantly differ between the RLS+ and RLS- subgroup, although there was a trend towards longer FMD duration in the RLS+ group. In 2 out of 10 patients with positive family history, RLS preceded FMD onset.

Regarding the motor phenomena present in lower limbs in 42 RLS+ patients, 27 patients $(64.3 \%)$ presented with functional gait disorder and/or functional weakness but no abnormal movements in lower limbs; 11 patients (26.2\%) presented with abnormal movements, that is, functional tremor, dystonia or myoclonus in the lower limbs; 4 patients $(9.5 \%)$ had no functional motor symptoms in lower limbs and their motor symptoms in the lower limbs were exclusively related to RLS.

\section{Sensory symptoms and pain in lower limbs}

Results of the assessment of sensory symptoms and pain in lower limbs are shown in table 4 . Both sensory symptoms and pain were more frequently found in patients with FMD than in controls. Sensory symptoms related exclusively to RLS were present in $12.9 \%$ of all patients with FMD (ie, in $30.4 \%$ of RLS+ patients).

\section{Questionnaires for non-motor symptoms}

Patients with FMD suffered from significantly more severe depression, anxiety, fatigue and daytime sleepiness than control subjects. The scores are shown in table 5 .

\section{Comparison between RLS+ and RLS- patients with FMD}

In the FMD group, no differences in demographic or clinical parameters were found between RLS+ and RLSgroups. No significant association between a specific motor phenotype and RLS status was observed (table 1).

On actigraphy, the RLS+ group showed a higher mean PLMi and a higher proportion of PLMi $\geq 22.5$ /hour than the RLS- group showed. Out of 96 patients with FMD who underwent actigraphy, 20 patients had both RLS and a PLMi $\geq 22.5 /$ hour.

Both sensory symptoms and/or pain in lower limbs were more frequent in RLS+ than in RLS- patients. No difference in mean pain intensity in last 4 weeks was found in RLS+ and RLS- groups.

No difference between the RLS+ andRLS- patients group was found in scales rating depression, anxiety and sleepiness and fatigue.

\section{Additional analysis}

Logistic regression among assessed clinical motor and non-motor parameters did not find any significant predictors of RLS+ status in patients with FMD ( $p=0.5)$. All above presented results remained unchanged after patients with FMD and organic neurological comorbidities were excluded. 
Table 3 Actigraphy

\begin{tabular}{|c|c|c|c|c|c|c|}
\hline & \multicolumn{3}{|c|}{ FMD patients vs controls } & \multicolumn{3}{|c|}{ RLS+ vs RLS- FMD patients } \\
\hline & $\begin{array}{l}\text { FMD patients } \\
(\mathrm{N}=96)\end{array}$ & $\begin{array}{l}\text { Controls } \\
(\mathrm{N}=76)\end{array}$ & $P$ value & FMD/RLS+ $(\mathrm{N}=42)$ & FMD/RLS- $(\mathrm{N}=54)$ & $P$ value \\
\hline PLMi $\geq 22.5 /$ hour (N) & 30 & 9 & $0.003^{*}$ & 20 & 10 & $0.002^{*}$ \\
\hline \% (95\% Cl) & 31.3 (23 to 41$)$ & $11.8(8$ to 21$)$ & & 47.6 (33 to 62$)$ & 18.5 (10 to 31$)$ & \\
\hline$\%(95 \% \mathrm{Cl})$ & 20.8 (14 to 30$)$ & 2.6 (1 to 9 ) & & - & - & - \\
\hline
\end{tabular}

*Significant results after correction for five comparisons $(p<0.05)$.

All intergroup comparisons were performed using Mann-Whitney $U$ test for quantitative parameters and $\chi^{2}$ for qualitative one. $P$ values shown are nominal uncorrected results.

FMD, functional movement disorder; PLM, periodic limb movements; PLMi, periodic limb movement index; RLS, restless legs syndrome.

\section{DISCUSSION}

This is the first case-control study to assess the prevalence of RLS in patients with FMD. Forty-three per cent of patients with FMD met the diagnostic criteria for RLS while in the control group RLS was found in $8 \%$, similarly to previous findings in population studies. ${ }^{22}$ The RLS presence was not associated with medication or organic comorbidities in patients with FMD.

However, only $21 \%$ of patients with FMD had both RLS and clinically relevant PLM detected by actigraphy. This result suggests there might be false-positive cases either due to suggestibility or due to functional symptoms mimicking RLS.

Known mimics included in the new RLS criteria were carefully excluded. Nevertheless, suggestibility inherent in an interview on symptoms that are not reported spontaneously and/or general tendency of patients with FMD to over-report symptoms might be a source of a diagnostic bias. Additionally, and perhaps more importantly, functional motor and sensory phenomena may mimic RLS symptoms in this group of patients.

However, even if we take into account only RLS cases with comorbid clinically relevant PLM, our findings still suggest FMD is associated with a twofold higher prevalence of RLS compared with general population. Also in healthy controls, we detected both RLS and clinically relevant PLM only in a small proportion (2.6\%) of cases.

RLS diagnosis was further supported by a higher occurrence of actigraphically detected PLM in RLS+ patients in comparison to both RLS- patients and controls.

The mean PLMi was higher in RLS- patients than in the control group, suggesting an association of PLM and FMD independent of RLS occurrence. Alternatively, some false-RLS- cases could be also included in

Table 4 Sensory symptoms and pain

\begin{tabular}{|c|c|c|c|c|c|c|}
\hline & \multicolumn{3}{|c|}{ FMD patients vs controls } & \multicolumn{3}{|c|}{ RLS+ vs RLS- FMD patients } \\
\hline & FMD patients & Controls & $P$ value & FMD/RLS+ & FMD/RLS- & $P$ value \\
\hline \multicolumn{7}{|c|}{ Sensory symptoms } \\
\hline $\begin{array}{l}\text { Number of } \\
\text { subjects }\end{array}$ & 96 & 76 & - & 42 & 54 & - \\
\hline Lower limbs & $83.3 \%$ & $9.2 \%$ & $<0.0001^{*}$ & $97.6 \% \dagger$ & $72.2 \%$ & $0.0005^{\star}$ \\
\hline $\begin{array}{l}\text { Exclusively to } \\
\text { RLS }\end{array}$ & $12.9 \%$ & $7.9 \%$ & 0.087 & $30.4 \%$ & - & - \\
\hline \multicolumn{7}{|l|}{ Pain } \\
\hline $\begin{array}{l}\text { Number of } \\
\text { subjects }\end{array}$ & 90 & 76 & - & 38 & 52 & - \\
\hline Lower limbs & $62.3 \%$ & $11.8 \%$ & $<0.0001^{*}$ & $75.0 \%$ & $48.2 \%$ & $0.009^{\star}$ \\
\hline $\begin{array}{l}\text { Mean VAS in } \\
4 \text { weeks (SD) }\end{array}$ & $5.6(3)$ & $1.4(2)$ & $<0.00001^{*}$ & $6.1(2)$ & $5.3(3)$ & 0.40 \\
\hline
\end{tabular}

All intergroup comparisons were performed using Mann-Whitney $U$ test for quantitative parameters and $\chi^{2}$ for qualitative ones, $p$ values shown are nominal uncorrected results.

*Significant results after correction for multiple testing for four comparisons $(p<0.05)$.

†Only one RLS+ patient did not report sensory symptoms as part of the RLS symptomatology, nevertheless he fulfilled the RLS criteria and his maximum PLMi was 33.

FMD, functional movement disorder; PLMi, periodic limb movement index; RLS, restless legs syndrome; VAS, Visual Analogue Scale. 
Table 5 Non-motor symptoms subjective questionnaires

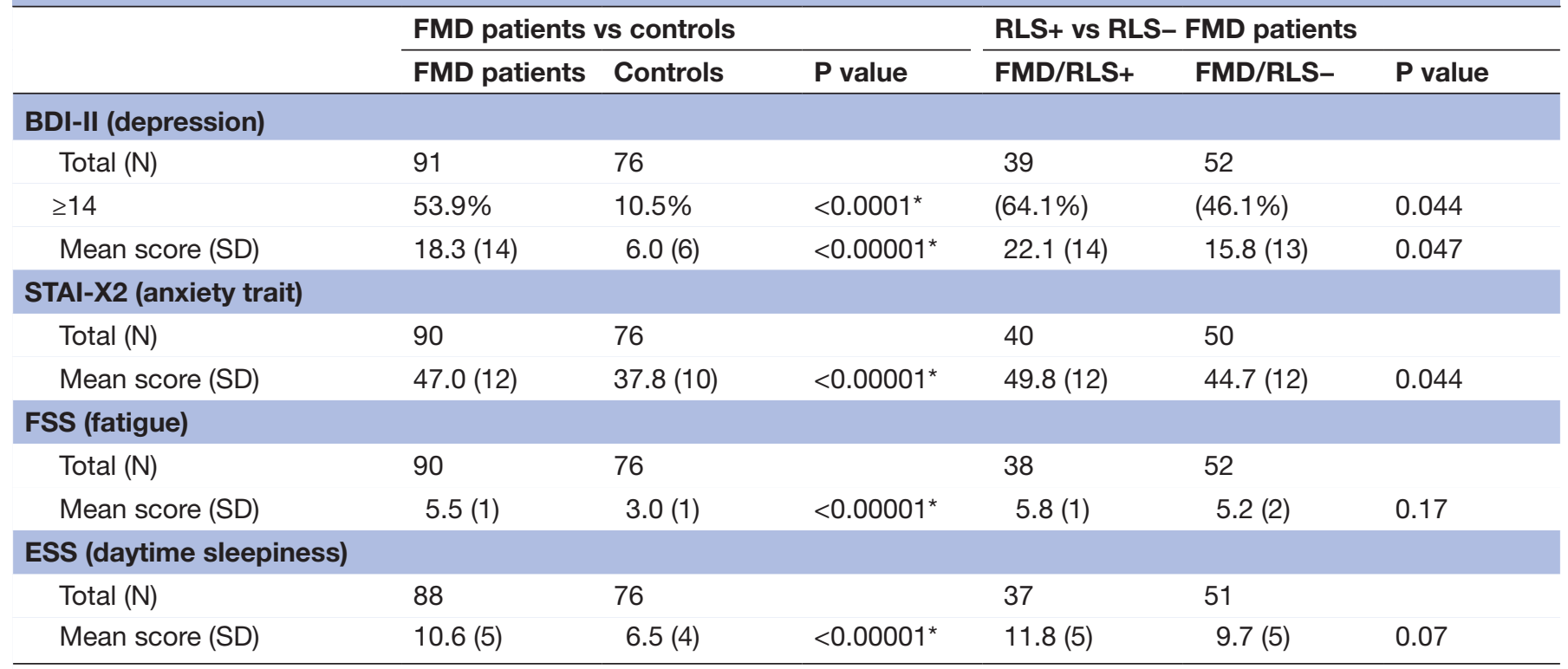

All intergroup comparisons were performed using Mann-Whitney $U$ test for quantitative parameters and $\chi^{2}$ for qualitative ones, $p$ values shown are nominal uncorrected results.

${ }^{*}$ Significant results after correction for multiple testing for four comparisons $(p<0.05)$.

BDI-II, Beck Depression Inventory II; ESS, Epworth Sleepiness Scale; FMD, functional movement disorder; FSS, Fatigue Severity Scale; RLS, restless legs syndrome; STAI-X2, State/Trait Anxiety Inventory X2.

this group, especially in the subgroup with PLMi $\geq 22.5 /$ hour. However, PLM may be associated with antidepressants intake which was higher in the FMD group and thus could contribute to PLM expression. ${ }^{10}$

Notably, no differences between RLS+ andRLSpatients were found in organic neurological and/ or somatic comorbidities, medication use or gender, suggesting that these factors do not affect RLS expression in patients with FMD.

The rate of familial RLS in our patients with FMD and control subjects was rather low compared with previous reports; however, in majority of cases the family history could not be reliably established. Low rate of familial cases would suggest stronger role of genetic factors in the development of RLS can be supposed only in a minority of patients with FMD. ${ }^{43}$

We did not find a relationship between the FMD phenotype and the presence of RLS or PLM. This result is in line with the current neurobiological model of FMD which suggests there may be common mechanisms acting in FMD, regardless of motor phenotype. ${ }^{7}$

To our surprise, in two-thirds of the RLS+ patients, RLS started concurrently with or after the FMD onset. In these patients, the burden resulting from a functional disorder might have contributed to RLS development rather than vice versa. However, FMD duration did not appear as a significant risk factor for RLS development.

The finding of the association between FMD and RLS/PLM suggests these conditions might share some common pathophysiological mechanisms. The genetic and molecular basis of FMD is still largely unknown. In RLS some pathophysiological genetic and molecular factors including dysfunction in iron homeostasis and iron-dopamine interaction, role of inflammation and hypoxia have been already elucidated. ${ }^{52}$ In RLS and PLM, clinical symptoms and also some neurophysiological abnormalities, such as short intracortical inhibition (SICI) in RLS and lower threshold for the production of spinal flexor reflexes in PLM, can be improved with dopaminergic drugs. ${ }^{25}{ }^{26} \mathrm{~A}$ loss of SICI has also been demonstrated at least in functional dystonia. ${ }^{27}$ In Parkinson's disease, where there is also loss of SICI, the deficit can be improved with dopaminergic drugs. ${ }^{28}$ Hence, a common state of reduced inhibition might be postulated due to dopamine deficiency.

Additionally, we may assume, similar environmental factors that trigger the manifestation of RLS symptoms, for example, cumulative number of diseases in a single individual, could also increase the risk of FMD in vulnerable individuals. ${ }^{5}$ Indeed, organic neurological comorbidity was higher in patients with FMD than in controls. Migraine was the most frequent comorbidity. Headache seems to be a common problem in patients with FMD, and migraine can even play a role as precipitating factor in functional motor symptoms development. ${ }^{29} 30$

Twenty-five per cent of patients were also diagnosed with other organic neurological condition. The co-occurrence of organic and functional disorders has been previously detected in patients diagnosed with psychogenic movement disorders and also in cohorts of patients with organic neurological disorders including movement disorders. $^{231-33}$

RLS severity according to the IRLS scale including reported weekly frequency and daily duration of the 
symptoms was high in the patients group. Therefore, we believe RLS should be taken into account as a serious comorbid condition, despite the general assumption that patients with FMD tend to over-report symptoms severity. In line with previous studies, sensory symptoms and pain were present in the vast majority of patients with functional neurological disorders. ${ }^{29} 34$ Patients with RLS reported more sensory symptoms and pain in lower limbs than patients without RLS. Sensations in lower limbs clinically attributable exclusively to RLS were only found in a minority of RLS+ patients. RLS sensory symptoms thus constituted a part of a wider spectrum of sensory disturbances in majority of patients. Similarly, in the vast majority of patients there was an anatomical overlap in distribution of the functional motor symptoms and motor symptoms related to RLS. However, the majority of patients with FMD presented with abnormal patterns of gait and weakness in lower limbs which are easily distinguishable from motor phenomena related to RLS.

Association between RLS and pain in the lower limbs is difficult to interpret. In this study, we did not consider the aetiology and detailed characteristics of pain. The uncomfortable sensations are described as painful in up to $30 \%-50 \%$ patients with RLS. ${ }^{4}$ Therefore, at least a part of what has been previously considered as chronic pain actually could be attributable to RLS in patients with FMD.

In accordance with the previous studies on FMD and other somatoform disorders, patients with FMD had higher scores of depression, anxiety, fatigue and daytime sleepiness than controls. ${ }^{3}$ Epidemiological evidence also suggests that there is an association between mood disorders and both RLS and functional symptoms. ${ }^{3} 833$ The causality of these factors is, however, impossible to determine.

Our study has limitations. Currently, polysomnography is the gold standard and only clinically acceptable means of quantifying periodic limb movements in sleep. ${ }^{6}$ We used a big toe-worn actigraphy to objectively assess nocturnal leg movements because of the logistic limitations of polysomnography use in this cohort size. However, the same actigraphic methodology was previously validated against polysomnography on the same night in our own laboratory which increases the reliability of this method. ${ }^{17}$ Another limitation is that new polysomnographic criteria for PLM have been recommended in the course of the study. ${ }^{35}$ However, these new criteria could not be implemented in this actigraphic study using validated methodology based on older criteria for PLM detection. ${ }^{17}$ Additionally, considering the low absolute number of RLS+ subjects in the control group, comparisons of parameters related to RLS (such as positive family history or RLS duration) suffer from low statistical power. Finally, apart from the ESS, we did not measure sleep quality using other subjective or objective measures. Sleep disturbance or restriction often exacerbates or triggers RLS, and so it may be that FMD RLS+ patients have poorer sleep than RLS- patients. RLS would be then associated with poor sleep related to psychobehavioural profiles rather than being directly associated with FMD, and those with an underlying predisposition to RLS reach the threshold of clinical RLS.

Further studies are needed to determine the RLS and PLM prevalence in FMD. The diagnosis of RLS seems to be challenging. Controlling for inner consistency in reporting RLS symptoms over time may help to differentiate RLS from functional symptoms. The efficacy of dopamine agonists would represent a supportive feature for the diagnosis and should be tested in clinical practice. However, evidence for dopamine agonists efficacy in this group should be studied in randomised control trials given the possible strong placebo effect in this group of patients.

On the other hand, based on these findings, functional motor and sensory symptoms could be considered as additional RLS mimics.

\section{CONCLUSIONS}

In conclusion, we found increased prevalence of RLS in patients with FMD. The presence of RLS was associated with a higher proportion of clinically relevant PLM and more frequent sensory symptoms and pain in lower limbs. However, further studies are needed to confirm these findings and determine the rate of false-positive diagnosis, that is, RLS mimics in this group of patients.

This finding could have several implications. RLS may be under-recognised in patients with FMD. Correct diagnosis and appropriate treatment of comorbid RLS may be important in patients with FMD as RLS is a common medical reason for sleep disturbance and impaired quality of life. ${ }^{36}$ Additionally, association between FMD and RLS/ PLM might be potentially relevant for future research of molecular and genetic factors in the pathophysiology of FMD which is still largely unknown.

Acknowledgements We thank Dana Fialová, Irena Stárková and Dana Suchá for administrative support.

Contributors All authors meet the ICMJE criteria for authorship. TS was responsible for the concept and design of the study, clinical data acquisition, data analysis and interpretation, and drafting of the original report which was reviewed and revised by all co-authors. MS was responsible for actigraphic data collection, all actigraphic analysis, data interpretation and drafting of the original report. DK was responsible for study design, clinical data acquisition, data analysis including statistics and interpretation and drafting of the original report. KŠ was responsible for clinical data acquisition, data analysis and interpretation. $\mathrm{MH}$ was responsible for data analysis and interpretation. ER was responsible for data analysis and interpretation. Funding was obtained by TS and ER.

Funding This study was supported by Ministry of Health of the Czech Republic, grant AZV ČR 16-29651. MH is supported by the NINDS Intramural Program.

Competing interests None declared.

Patient consent for publication Not required.

Ethics approval Ethics Committee of the General University Hospital in Prague (approval number 26/15 Grant).

Provenance and peer review Not commissioned; externally peer reviewed. Data sharing statement There are no additional unpublished data from the study. Open access This is an open access article distributed in accordance with the Creative Commons Attribution Non Commercial (CC BY-NC 4.0) license, which 
permits others to distribute, remix, adapt, build upon this work non-commercially, and license their derivative works on different terms, provided the original work is properly cited, appropriate credit is given, any changes made indicated, and the use is non-commercial. See: http://creativecommons.org/licenses/by-nc/4.0/.

\section{REFERENCES}

1. Edwards MJ, Bhatia KP. Functional (psychogenic) movement disorders: merging mind and brain. Lancet Neurol 2012;11:250-60.

2. Factor SA, Podskalny GD, Molho ES. Psychogenic movement disorders: frequency, clinical profile, and characteristics. J Neurol Neurosurg Psychiatry 1995;59:406-12.

3. Gelauff J, Stone J, Edwards M, et al. The prognosis of functional (psychogenic) motor symptoms: a systematic review. J Neurol Neurosurg Psychiatry 2014;85:220-6.

4. Allen RP, Picchietti DL, Garcia-Borreguero D, et al. Restless legs syndrome/Willis-Ekbom disease diagnostic criteria: updated International Restless Legs Syndrome Study Group (IRLSSG) consensus criteria-history, rationale, description, and significance. Sleep Med 2014;15:860-73.

5. Trenkwalder C, Allen R, Högl B, et al. Restless legs syndrome associated with major diseases: A systematic review and new concept. Neurology 2016;86:1336-43.

6. Plante DT. Leg actigraphy to quantify periodic limb movements of sleep: a systematic review and meta-analysis. Sleep Med Rev 2014;18:425-34.

7. Edwards MJ, Adams RA, Brown H, et al. A Bayesian account of 'hysteria'. Brain 2012;135:3495-512.

8. Becker PM, Sharon D. Mood disorders in restless legs syndrome (Willis-Ekbom disease). J Clin Psychiatry 2014;75:e679-e694.

9. Szentkirályi A, Völzke H, Hoffmann W, et al. Multimorbidity and the risk of restless legs syndrome in 2 prospective cohort studies. Neurology 2014;82:2026-33.

10. Haba-Rubio J, Marti-Soler H, Marques-Vidal P, et al. Prevalence and determinants of periodic limb movements in the general population. Ann Neurol 2016;79:464-74.

11. Gupta A, Lang AE. Psychogenic movement disorders. Curr Opin Neurol 2009;22:430-6.

12. Daum C, Hubschmid M, Aybek S. The value of 'positive' clinical signs for weakness, sensory and gait disorders in conversion disorder: a systematic and narrative review. J Neurol Neurosurg Psychiatry 2014;85:180-90.

13. Espay AJ, Lang AE. Phenotype-specific diagnosis of functional (psychogenic) movement disorders. Curr Neurol Neurosci Rep 2015;15:32

14. Headache Classification Committee of the International Headache Society (IHS). The International Classification of Headache Disorders, 3rd edition (beta version). Cephalalgia 2013;33:629-808.

15. Beck AT, Ward $\mathrm{CH}$, Mendelson $\mathrm{M}$, et al. An inventory for measuring depression. Arch Gen Psychiatry 1961;4:561-71.

16. Walters AS, LeBrocq C, Dhar A, et al. Validation of the international restless legs syndrome study group rating scale for restless legs syndrome. Sleep Med 2003;4:121-32.
17. Kemlink D, Pretl M, Sonka K, et al. A comparison of polysomnographic and actigraphic evaluation of periodic limb movements in sleep. Neurol Res 2008;30:234-8.

18. Freynhagen $R$, Baron $R$, Gockel U, et al. painDETECT: a new screening questionnaire to identify neuropathic components in patients with back pain. Curr Med Res Opin 2006;22:1911-20.

19. Spielberger CD. STAI: Manual for the Stait-Trait Anxiety Inventory. Palo Alto: Consulting Psychologists Press, 1983.

20. Krupp LB, LaRocca NG, Muir-Nash J, et al. The fatigue severity scale. Application to patients with multiple sclerosis and systemic lupus erythematosus. Arch Neurol 1989;46:1121-3.

21. Johns MW. A new method for measuring daytime sleepiness: the Epworth sleepiness scale. Sleep 1991;14:540-5.

22. Koo BB. Restless Leg Syndrome Across the Globe: Epidemiology of the Restless Legs Syndrome/Willis-Ekbom Disease. Sleep Med Clin 2015;10:189-205.

23. Montplaisir J, Boucher S, Poirier G, et al. Clinical, polysomnographic, and genetic characteristics of restless legs syndrome: a study of 133 patients diagnosed with new standard criteria. Mov Disord 1997;12:61-5.

24. Earley CJ, Connor J, Garcia-Borreguero D, et al. Altered brain iron homeostasis and dopaminergic function in Restless Legs Syndrome (Willis-Ekbom Disease). Sleep Med 2014;15:1288-301.

25. Magalhães SC, Kaelin-Lang A, Sterr A, et al. Transcranial magnetic stimulation for evaluation of motor cortical excitability in restless legs syndrome/Willis-Ekbom disease. Sleep Med 2015;16:1265-73.

26. Bara-Jimenez W, Aksu M, Graham B, et al. Periodic limb movements in sleep: state-dependent excitability of the spinal flexor reflex. Neurology 2000;54:1609-16.

27. Espay AJ, Morgante F, Purzner J, et al. Cortical and spinal abnormalities in psychogenic dystonia. Ann Neurol 2006;59:825-34.

28. Cantello R, Tarletti R, Civardi C. Transcranial magnetic stimulation and Parkinson's disease. Brain Res Brain Res Rev 2002;38:309-27.

29. Stone J, Warlow C, Sharpe M. The symptom of functional weakness: a controlled study of 107 patients. Brain 2010;133:1537-51.

30. Pareés I, Kojovic M, Pires C, et al. Physical precipitating factors in functional movement disorders. J Neurol Sci 2014;338:174-7.

31. Stone J, Carson A, Duncan R, et al. Who is referred to neurology clinics?-the diagnoses made in 3781 new patients. Clin Neurol Neurosurg 2010;112:747-51.

32. Onofrj M, Bonanni L, Manzoli L, et al. Cohort study on somatoform disorders in Parkinson disease and dementia with Lewy bodies. Neurology 2010;74:1598-606.

33. Feinstein A, Stergiopoulos V, Fine J, et al. Psychiatric outcome in patients with a psychogenic movement disorder: a prospective study. Neuropsychiatry Neuropsychol Behav Neurol 2001;14:169-76.

34. Schrag A, Trimble M, Quinn N, et al. The syndrome of fixed dystonia: an evaluation of 103 patients. Brain 2004;127:2360-72.

35. Ferri R, Fulda S, Allen RP, et al. World Association of Sleep Medicine (WASM) 2016 standards for recording and scoring leg movements in polysomnograms developed by a joint task force from the International and the European Restless Legs Syndrome Study Groups (IRLSSG and EURLSSG). Sleep Med 2016;26:86-95.

36. Kushida C, Martin M, Nikam P, et al. Burden of restless legs syndrome on health-related quality of life. Qual Life Res 2007;16:617-24. 